\title{
Fibre Reinforced Polyester Composites
}

\author{
Salar Bagherpour
}

Additional information is available at the end of the chapter

http://dx.doi.org/10.5772/48697

\section{Introduction}

A composite material is a non uniform solid consisting of two or more different materials that are mechanically bonded together. Each of the various components retains its identity in the composite and maintains its characteristic structure and properties. Generally, the structure of a composite consists of two phases, matrix and reinforcement. The matrix is a continuous phase and the reinforcement is a discontinuous one. The duty of reinforcements is attaining strength of the composite and the matrix has the responsibility of bonding of the reinforcements. There are recognizable interface between the materials of matrix and reinforcements. The composite materials, however, generally possess combination of properties such as stiffness, strength, weight, high temperature performance, corrosion resistance, hardness and conductivity which are not possible with the individual components. Indeed, composites are produced when two or more materials or phases are used together to give a combination of properties that cannot be achieved otherwise. Composite materials especially the fiber reinforced polyester (FRP) kind highlight how different materials can work in synergy. Analysis of these properties shows that they depend on (1) the properties of the individual components; (2) the relative amount of different phases; (3) the orientation of various components; the degree of bonding between the matrix and the reinforcements and (4) the size, shape and distribution of the discontinuous phase. The material involves can be organics, metals or ceramics. Therefore, a wide range of freedom exists, and composite materials can often be designed to meet a desired set of engineering properties and characteristics [1].

There are many types of composite materials and several methods of classifying them. One method is based on the matrix materials which include polymers, metals and ceramics. The other method is based on the reinforcement phase which has the shape of fiber, particulate and whisker. Whiskers are like fibers but their length is shorter. The bonding between the particles, fibers or whiskers and the matrix is also very important. In structural composites, polymeric molecules known as coupling agent are used. These molecules form bonds with 
the dispersed phase and become integrated into the continuous matrix phase as well. The most popular type of composite material is the fiber-reinforced polyester composites, in which continuous thin fibers of one material such as glass, carbon or natural fibers are embedded in a polyester matrix. They are also called glass fiber reinforced polyester (GFRP), carbon fiber reinforced polyester (CFRP) and natural fiber reinforced polyester (NFRP). The objective is usually to enhance strength, stiffness, fatigue, resistance, or strength to weight ratio by incorporating strong and stiff fibers in a softer, more ductile matrix. The microstructure of a selected GFRP composite is shown in figure 1.

The usages of fiber reinforced polyesters are in airplanes, electronics components, automotives, rail ways and wagon systems and sporting equipments. Beside their desired mechanical properties, their resistance to corrosion is also a tempting factor to use these composite in different areas. Although they are sensitive to UV light, heat and moisture environments, good maintenance could increase their life time. In this chapter different phases of FRPs, the mechanical relationships between different components of FRPs, the mechanism of degradation and aging of FRPs and application of them is discussing [2].

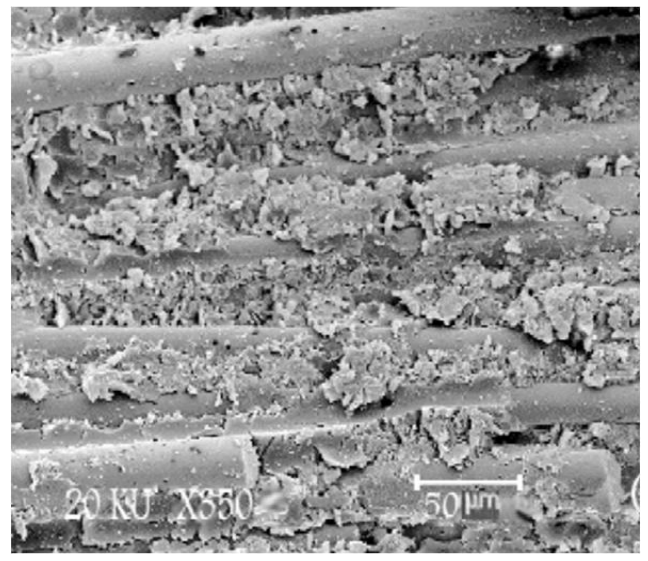

Figure 1. Microstructure of glass fibre reinforced polyester composite.

\section{Different phases of FRP composites}

\subsection{Fiber reinforcements}

The fiber is an important constituent in FRP composites. A great deal of research and development has been done with the fibers on the effects in the types, volume fraction, architecture, and orientations. The fiber generally occupies $30 \%-70 \%$ of the matrix volume in the composites. The fibers can be chopped, woven, stitched, and braided. They are usually treated with sizing such as starch, gelatin, oil or wax to improve the bond as well as binders to improve the handling. The most common types of fibers used in advanced composites for structural applications are the fiberglass, aramid, and carbon. The fiberglass is the least expensive and carbon being the most expensive. The cost of aramid fibers is 
about the same as the lower grades of the carbon fiber. Other high-strength high-modulus fibers such as boron are at the present time considered to be economically prohibitive.

\subsection{Glass fibers}

The glass fibers are divided into three main classes E-glass, S-glass and C-glass. The E-glass is designated for electrical use and the S-glass for high strength. The C-glass is for high corrosion resistance, and it is uncommon for civil engineering application. Of the three fibers, the E-glass is the most common reinforcement material used in civil and industrial structures. It is produced from lime-alumina-borosilicate which can be easily obtained from abundance of raw materials like sand. The fibers are drawn into very fine filaments with diameters ranging from 2 to $13 \times 10^{-6} \mathrm{~m}$. The glass fiber strength and modulus can degrade with increasing temperature. Although the glass material creeps under a sustained load, it can be designed to perform satisfactorily. The fiber itself is regarded as an isotropic material and has a lower thermal expansion coefficient than that of steel [3].

There are also the other fiber glasses which are used for FRP reinforcement as well as;

- A-glass, soda lime silicate glasses used where the strength, durability, and good electrical resistivity of E-glass are not required.

- D-glass, borosilicate glasses with a low dielectric constant for electrical applications.

- ECR-glass, calcium alumino silicate glasses with a maximum alkali content of $2 \mathrm{wt} \%$ used where strength, electrical resistivity, and acid corrosion resistance are desired.

- AR-glass, alkali resistant glasses composed of alkali zirconium silicates used in cement substrates and concrete.

- R-glass, calcium alumino silicate glasses used for reinforcement where added strength and acid corrosion resistance are required.

- S-2-glass, magnesium alumino silicate glasses used for textile substrates or reinforcement in composite structural applications which require high strength, modulus, and stability under extreme temperature and corrosive environments.

Table 1 and 2 show the chemical and mechanical properties of different glass fibers respectively.

\subsubsection{Aramid fibers}

These are synthetic organic fibers consisting of aromatic polyamides. The aramid fibers have excellent fatigue and creep resistance. Although there are several commercial grades of aramid fibers available, the three most common ones used in structural applications are Kevlar 29, Kevlar 49 and Kevlar 149. The Young's Modulus curve for Kevlar 29 is linear to a value of $83 \mathrm{GPa}$ but then becomes slightly concave upward to a value of $100 \mathrm{GPa}$ at rupture; whereas, for Kevlar 49 the curve is linear to a value of $124 \mathrm{GPa}$ at rupture (see Table 3). As an anisotropic material it's transverse and shear modulus are an order of magnitude less than those in the longitudinal direction. The fibers can have difficulty achieving a chemical or mechanical bond with the resin [4]. 


\begin{tabular}{|l|c|c|c|c|c|c|c|c|}
\hline & A-glass & C-glass & D-glass & E-glass & $\begin{array}{c}\text { ECR- } \\
\text { glass }\end{array}$ & $\begin{array}{c}\text { AR- } \\
\text { Glass }\end{array}$ & R-glass & $\begin{array}{c}\text { S-2- } \\
\text { glass }\end{array}$ \\
\hline $\mathrm{SiO} \%$ & & & & & & & & \\
\hline $\mathrm{A} 2 \mathrm{O} 3 \%$ & $0-72$ & $64-68$ & $72-75$ & $52-56$ & $54-62$ & $55-75$ & $55-60$ & $64-66$ \\
\hline $\mathrm{B} 2 \mathrm{O} 3 \%$ & $0-6$ & $4-6$ & $21-24$ & $5-10$ & & $0-8$ & $0-0.35$ & \\
\hline $\mathrm{CaO} \%$ & $6-10$ & $11-15$ & $0-1$ & $16-25$ & $17-25$ & $1-10$ & $8-15$ & $0-0.2$ \\
\hline $\mathrm{MgO} \%$ & $0-4$ & $2-4$ & & $0-5$ & $0-4$ & & $4-7$ & $9.5-10$ \\
\hline $\mathrm{ZnO} \%$ & & & & & $2-5$ & & & \\
\hline $\mathrm{BaO} \%$ & & $0-1$ & & & & & & \\
\hline $\mathrm{Li2O} \%$ & & & & & & $0-1.5$ & & \\
\hline $\mathrm{Na} 2 \mathrm{O}+\mathrm{K} 2 \mathrm{O} \%$ & $14-16$ & $7-10$ & $0-4$ & $0-2$ & $0-2$ & $11-21$ & $0-1$ & $0-0.2$ \\
\hline $\mathrm{TiO} \%$ & $0-0.6$ & & & $0-4$ & $0-4$ & $0-12$ & & \\
\hline $\mathrm{ZrO} \%$ & & & & & & $1-18$ & & \\
\hline $\mathrm{Fe} 2 \mathrm{O} \%$ & $0-0.5$ & $0-0.8$ & $0-0.3$ & $0-0.8$ & $0-0.8$ & $0-5$ & $0-0.5$ & $0-0.1$ \\
\hline $\mathrm{F} 2 \%$ & $0-0.4$ & & & & & $0-5$ & $0-0.3$ & \\
\hline
\end{tabular}

Table 1. Chemical composition of different glass fibers.

\begin{tabular}{|l|c|c|c|c|c|c|c|c|}
\hline & $\begin{array}{c}\text { A- } \\
\text { glass }\end{array}$ & $\begin{array}{c}\text { C- } \\
\text { glass }\end{array}$ & D-glass & $\begin{array}{c}\text { E- } \\
\text { glass }\end{array}$ & $\begin{array}{c}\text { ECR- } \\
\text { glass }\end{array}$ & $\begin{array}{c}\text { AR- } \\
\text { Glass }\end{array}$ & $\begin{array}{c}\text { R- } \\
\text { glass }\end{array}$ & $\begin{array}{c}\text { S-2- } \\
\text { glass }\end{array}$ \\
\hline Density (gr/cm3) & 2.44 & 2.52 & $\begin{array}{c}2.11- \\
2.14\end{array}$ & 2.58 & 2.72 & 2.70 & 2.54 & 2.46 \\
\hline $\begin{array}{l}\text { Tensile Strength }(\mathrm{MPa}) \text { at - } \\
196^{\circ} \mathrm{C}\end{array}$ & & 5380 & & 5310 & 5310 & & & 8275 \\
\hline Tensile Strength at $23^{\circ} \mathrm{C}$ & 3310 & 3310 & 2415 & 3445 & 3445 & 3241 & 4135 & 4890 \\
\hline Tensile Strength at $371^{\circ} \mathrm{C}$ & & & & 2620 & 2165 & & 2930 & 4445 \\
\hline Tensile Strength at $538^{\circ} \mathrm{C}$ & & & & 1725 & 1725 & & 2140 & 2415 \\
\hline $\begin{array}{l}\text { Modulus of Elasticity }(\mathrm{GPa}) \\
\text { at } 23^{\circ} \mathrm{C}\end{array}$ & 68.9 & 68.9 & 51.7 & 72.3 & 80.3 & 73.1 & 85.5 & 86.9 \\
\hline Modulus of Elasticity at $538^{\circ} \mathrm{C}$ & & & & 81.3 & 81.3 & & & 88.9 \\
\hline Elongation\% & 4.8 & 4.8 & 4.6 & 4.8 & 4.8 & 4.4 & 4.8 & 5.7 \\
\hline
\end{tabular}

Table 2. Mechanical properties of different glass fibers.

\begin{tabular}{|l|c|c|c|}
\hline Fibers & Tensile Strength (MPa) & Modulus of Elasticity (GPa) & Density (gr/cm3) \\
\hline Kevlar 29 & 2920 & $83-100$ & 1.43 \\
\hline Kevlar 49 & 3000 & 124 & 1.44 \\
\hline Kevlar 149 & 3450 & 143 & 1.47 \\
\hline
\end{tabular}

Table 3. Mechanical properties of aramid fibers. 


\subsubsection{Carbon fibers}

Carbon fibers refer to fibers which are at least $92 \mathrm{wt} . \%$ carbon in composition. They can be short or continuous; their structure can be crystalline, amorphous, or partly crystalline. The crystalline form has the crystal structure of graphite (Figure 2), which consists of sp2 hybridized carbon atoms arranged two-dimensionally in a honeycomb structure in the $x-y$ plane. Carbon atoms within a layer are bonded by (1) covalent bonds provided by the overlap of the sp2 hybridized orbitals, and (2) metallic bonding provided by the delocalization of the $\mathrm{p}_{z}$ orbitals, i.e., the $\pi$ electrons. This delocalization makes graphite a good electrical conductor and a good thermal conductor in the $x-y$ plane. The bonding between the layers is Vander Waals bonding, so the carbon layers can easily slide with respect to one another; graphite is an electrical insulator and a thermal insulator perpendicular to the layers. Due to the difference between the in-plane and out-of-plane bonding, graphite has a high modulus of elasticity parallel to the plane and a low modulus perpendicular to the plane. Thus, graphite is highly anisotropic.

The high modulus of a carbon fiber stems from the fact that the carbon layers, though not necessarily flat, tend to be parallel to the fiber axis. This crystallographic preferred orientation is known as a fiber texture. As a result, a carbon fiber has a higher modulus parallel to the fiber axis than perpendicular to the fiber axis. Similarly, the electrical and thermal conductivities are higher along the fiber axis, and the coefficient of thermal expansion is lower along the fiber axis.

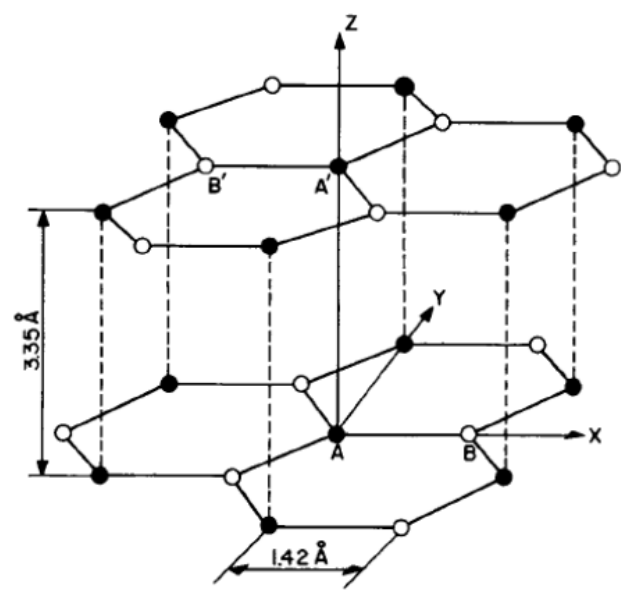

Figure 2. The crystal structure of graphite.

The proportion of graphite in a carbon fiber can range from 0 to $100 \%$. When the proportion is high, the fiber is said to be graphitic, and it is called a graphite fiber. However, a graphite fiber is polycrystalline, whereas a graphite whisker is a single crystal with the carbon layer rolled up like a scroll. Because of their single crystal nature, graphite whiskers are virtually flaw-free and have exceptionally high strength. However, the production yield of graphite whiskers is too low for them to be commercially significant. 
Commercial carbon fibers are fabricated by using pitch or polyacrylonitrile (PAN) as the precursor. Precursor fibers are fabricated by conventional spinning techniques, such as wet spinning for PAN and melt spinning for pitch. They must be converted to a form which is flameproof and stable at the high temperatures $\left(>700^{\circ} \mathrm{C}\right)$ involved in carbonization. Therefore, before carbonization (pyrolysis), they are stabilized for the case of the PAN precursor, or infusiblized for the case of the pitch precursor. Both stabilization and infusiblization are carried out in an oxidizing atmosphere. After that, general-purpose and high-performance fibers are obtained by carbonization in an inert atmosphere, followed by graphitization at $>2500^{\circ} \mathrm{C}$ in an inert atmosphere if a high modulus is desired, whereas activated carbon fibers are obtained by activating in a reactive atmosphere, such as steam at elevated temperatures. To enhance the preferred orientation in the high-performance carbon fibers, graphitization can be performed while the fibers are under tension. The higher the graphitization temperature, the greater the preferred orientation.

For the case of pitch as the precursor, isotropic pitch gives an isotropic carbon fiber, which belongs to the category of general-purpose carbon fibers, whereas anisotropic pitch (such as mesophase pitch) gives high-performance carbon fibers which have the carbon layers preferentially parallel to the fiber axis.

Surface treatments of carbon fibers are essential for improving the bonding between the fibers and the polymer matrix. They involve oxidation treatments and the use of coupling agents, wetting agents, and/or sizing (coatings). Carbon fibers need treatment both for thermosets and thermoplasts. As the processing temperature is usually higher for thermoplasts than thermosets, the treatment must be stable to a higher temperature (300400 "C) when a thermoplast is used.

Although there are many carbon fibers available on the open market, they can be arbitrarily divided into three grades as shown in Table 4. They have lower thermal expansion coefficients than both the glass and aramid fibers. The carbon fiber is an anisotropic material, and its transverse modulus is an order of magnitude less than its longitudinal modulus. The material has a very high fatigue and creep resistance.

\begin{tabular}{|l|c|c|c|}
\hline Fibers & $\begin{array}{c}\text { Tensile Strength } \\
\text { (MPa) }\end{array}$ & $\begin{array}{c}\text { Modulus of Elasticity } \\
\text { (GPa) }\end{array}$ & $\begin{array}{c}\text { Density } \\
\text { (gr/cm3) }\end{array}$ \\
\hline Carbon, High strength & 2480 & 230 & 1.8 \\
\hline Carbon, High Modulus & 1790 & 370 & 1.9 \\
\hline Carbon, ultra High Modulus & $1030-1310$ & $520-620$ & $2.0-2.1$ \\
\hline
\end{tabular}

Table 4. Mechanical properties of carbon fibers.

Since its tensile strength decreases with increasing modulus, its strain at rupture will also be much lower. Because of the material brittleness at higher modulus, it becomes critical in joint and connection details, which can have high stress concentrations. As a result of this phenomenon, carbon composite laminates are more effective with adhesive bonding that eliminates mechanical fasteners [5]. 


\subsubsection{Polyethylene fibers}

A high strength, high modulus polyethylene fiber called Spectra ${ }^{\mathrm{TM}}$ was developed at Allied Signal Technologies during the 1980s. The Spectra is based on ultra-high-molecular-weight polyethylene (UHMWPE). It has a specific gravity of 0.97 , meaning that it is the only reinforcing fiber available that is lighter than water. The Spectra is available in three classification (spectra 900, 1000 and 2000). Nominal properties are listed in table 5. The high specific strength of the fibers makes it appropriate for tensile application. The glass transition temperature of UHMWPE is in the range of $-20^{\circ} \mathrm{C}$ to $0^{\circ} \mathrm{C}$, and hence the fiber is in the rubbery state at room temperature and exhibits time-dependent (viscoelastic) behavior. This feature imparts outstanding impact resistance and toughness, but lead to undesirable creep effects under long-term sustained loading. The melting temperature of the fiber is 147 ${ }^{\circ} \mathrm{C}$, and hence use of polyethylene fibers is limited to relatively modest temperatures.

\begin{tabular}{|l|c|c|c|}
\hline Fibers & Tensile Strength (MPa) & Modulus of Elasticity (GPa) & Density $\left(\mathbf{g r} / \mathbf{c m}^{\mathbf{3}}\right)$ \\
\hline Spectra 900 & 2600 & 70 & $0.93-1.45$ \\
\hline Spectra 1000 & 3200 & 105 & $0.93-1.45$ \\
\hline Spectra 2000 & 3400 & 115 & $0.93-1.45$ \\
\hline
\end{tabular}

Table 5. Mechanical properties of Carbon fibers.

\subsection{Resin systems of the matrix}

The resin is another important constituent in composites. The two classes of resins are the thermoplastics and thermosets. A thermoplastic resin remains as solid at room temperature. It melts when heated and solidifies when cooled. The long-chain polymers do not chemically cross link. Because they do not cure permanently, they are undesirable for structural application. Conversely, a thermosetting resin will cure permanently by irreversible cross linking at elevated temperatures. This characteristic makes the thermoset resin composites very desirable for structural applications. The most common resins used in composites are the unsaturated polyesters, epoxies, and vinyl esters; the least common ones are the polyurethanes and phenolics.

\subsubsection{Polyester resins}

Generally polyester resins can be made by a dibasic organic acid and a dihydric alcohol. They can be classified as saturated polyester, such as polyethylene terephthalate, and unsaturated polyester. To form the network of the composite matrix, the unsaturated group or double bond needs to exist in a portion of 8 the dibasic acid. By varying the acid and alcohol, a range of polyester resins can be made. Orthophthalic polyesters are made by phthalic anhydride with either maleic anhydride or fumaric acid. Isophthalic polyesters, however, are made from isophthalic acid or terephthalic acid. The polyester resin is usually dissolved in monomer (styrene is the most widely used), which will copolymerize with it and contribute to the final properties of the cured resin. The addition of catalyst will cause the resin to cure. The most frequently used catalyst is methyl ethyl ketone peroxide (MEKP) 
or benzoyl peroxide (BPO) and the amount varies from 1-2\%. The catalyst will decompose in the presence of the polyester resin to form free radicals, which will attack the unsaturated groups (like $\mathrm{C}=\mathrm{C}$ ) to initiate the polymerization. The processing temperature and the amount of the catalyst can control the rate of polymerization, the higher temperature or the more the catalyst, the faster the reaction. After the resin turned from liquid to brittle solid, post cure at higher temperature may need to be done. The purpose of the post cure is to increase $\mathrm{Tg}$ of the resin by complete cross-linking. The properties of the polyester resin are affected by the type and amount of reactant, catalyst and monomers as well as the curing temperature. The higher the molecular weight of polyester and the more points of unsaturation in molecules, the higher is the strength of the cured resins. Orthophthalic polyesters are environmentally sensitive and have limited mechanical properties. They have been replaced in some applications by isophthalic polyesters due to the excellent environment resistance and improved mechanical properties of the latter.

The unsaturated polyester amounts to about $75 \%$ of all polyester resins used in the world. It is produced by the condensation polymerization of dicarboxylic acids and dihydric alcohols. The formulation contains an unsaturated material such as maleic anhydride or fumaric acid which is a part of the dicarboxylic acid component. The formulation affects the viscosity, reactivity, resiliency and heat deflection temperature (HDT). The viscosity controls the speed and degree of wet-out (saturation) of the fibers. The reactivity affects cure time and peak exotherm (heat generation) temperatures. High exotherm is needed for a thin section curing at room temperature and low exotherm for a thick section. Resiliency or flexible grade composites have a higher elongation, lower modulus and HDT. The HDT is a short term thermal property which measures the thermal sensitivity and stability of the resins. The advantages cited in the unsaturated polyester are its dimensional stability and affordable cost. Other advantages include ease in handling, processing, and fabricating. Some of the special formulations are high corrosion resistant and fire retardants. This resin is probably the best value for a balance between performance and structural capabilities [3,4].

\subsubsection{Epoxies}

The epoxies used in composites are mainly the glycidyl ethers and amines. The material properties and cure rates can be formulated to meet the required performance. Epoxies are generally found in marine, automotive, electrical and appliance applications. The high viscosity in epoxy resins limits it use to certain processes such as molding, filament winding, and hand lay-up. The right curing agent should be carefully selected because it will affect the type of chemical reaction, pot life and final material properties. Although epoxies can be expensive, it may be worth the cost when high performance is required. Table 6 shows mechanical properties of polyester and epoxy resins.

\subsubsection{Vinyl esters}

The vinyl ester resins were developed to take advantage of both the workability of the epoxy resins and the fast curing of the polyesters. The vinyl ester has higher physical properties than polyesters but costs less than epoxies. The acrylic esters are dissolved in a 
styrene monomer to produce vinyl ester resins which are cured with organic peroxides. A composite product containing a vinyl ester resin can withstand high toughness demand and offer excellent corrosion resistance [3].

\begin{tabular}{|c|c|c|c|c|c|}
\hline & Composition (Amorphous) & Use & $\begin{array}{l}\text { Tensile } \\
\text { Strength } \\
(\mathrm{MPa})\end{array}$ & $\begin{array}{l}\text { Modulus } \\
\text { of } \\
\text { Elasticity } \\
(\mathrm{GPa})\end{array}$ & $\begin{array}{l}\text { Density } \\
\left(\mathrm{gr} / \mathrm{cm}^{3}\right)\end{array}$ \\
\hline Polyesters & $\left(\begin{array}{ccc}\mathrm{O} & \mathrm{O} & \mathrm{CH}_{2} \mathrm{OH} \\
-\mathrm{C}-\left(\mathrm{CH}_{2}\right)_{\mathrm{m}}-\mathrm{C}-\mathrm{O}-\stackrel{\mathrm{C}}{\mathrm{C}}- & \\
& & \mathrm{CH}_{2} \mathrm{OH}\end{array}\right)_{n}$ & $\begin{array}{l}\text { Fiber glass, } \\
\text { laminate }\end{array}$ & $40-85$ & $1.3-4.5$ & $1.1-1.4$ \\
\hline Epoxies & $\left(\begin{array}{cc}\mathrm{CH}_{3} & \mathrm{OH} \\
\mid & \mid \\
-\mathrm{O}-\mathrm{C}_{6} \mathrm{H}_{4}-\mathrm{C}-\mathrm{C}_{6} \mathrm{H}_{4}-\mathrm{O}-\mathrm{CH}_{2}-\mathrm{CH}-\mathrm{CH}_{2}- & \\
\mathrm{CH}_{3} & \end{array}\right)$ & $\begin{array}{l}\text { Fiber glass, } \\
\text { adhesives }\end{array}$ & $40-85$ & $2.1-5.5$ & $1.2-1.4$ \\
\hline & Flexural Strength (MPa) & $\begin{array}{c}\text { Compressive } \\
\text { Strength }(\mathrm{MPa})\end{array}$ & $\begin{array}{c}\text { Fracture } \\
\text { Toughness } \\
\text { KIc (MPa m } \\
1 / 2)\end{array}$ & \multicolumn{2}{|c|}{$\begin{array}{l}\text { Thermal Expansion } \\
\qquad\left(10^{-6} \mathrm{~K}^{-1}\right)\end{array}$} \\
\hline Polyesters & 205- 690 & $140-410$ & 0.5 & \multicolumn{2}{|c|}{$100-200$} \\
\hline Epoxies & $1000-1500$ & $150-825$ & $0.6-1.0$ & \multicolumn{2}{|c|}{$55-110$} \\
\hline
\end{tabular}

Table 6. Mechanical properties of polyester and epoxy resins.

\section{Mechanical relationships in FRP composites}

Improved strength, fatigue resistance, Young`s modulus, and strength to weight ratio are provided in most fiber reinforced composites by incorporating strong, stiff, but brittle fibers into a softer, more ductile matrix. The matrix material transmits the force to the fibers, which carry most of the applied force. The matrix also provides protection for the fiber surface and minimizes diffusion of species such as oxygen or moisture that can degrade the mechanical properties of fibers. The strength of the composite may be high at both room temperature and elevated temperatures.

\subsection{Tensile properties}

The mechanical properties of FRPs are related to the mechanical properties and fractional volume of each phases, matrix and reinforcement. This is called the rule of mixture. By using the rule of mixture the properties as well as strength, modulus of elasticity, density, electrical and thermal conductivity are predictable. For example if $\rho_{\mathrm{c}}$ is density of a composite and $\rho_{\mathrm{c}, \mathrm{Q} 2}, \ldots$, Qn and $f_{1}, f_{2}, \ldots f_{n}$ are the densities and volume fraction of each phases respectively in the composite, the $\rho_{\mathrm{c}}$ is according to relation 1. 


$$
\rho_{c}=\sum\left(\mathrm{f}_{\mathrm{j}} \cdot \rho_{\mathrm{j}}\right)=\mathrm{f}_{1} \rho_{1}+\mathrm{f}_{2} \rho_{2}+\cdots+\mathrm{f}_{\mathrm{n}} \rho_{\mathrm{n}}
$$

So according to the rule of mixture the density of a FRP composite is :

$$
\rho_{\mathrm{c}}=\mathrm{f}_{\mathrm{m}} \rho_{\mathrm{m}}+\mathrm{f}_{\mathrm{f}} \rho_{\mathrm{f}}
$$

Where the subscripts $m$ and $f$ refer to the matrix and fiber. Note that $\mathrm{f}_{m}=1-\mathrm{f}_{f}$.

In addition the rule of mixture is used to predict the modulus of elasticity when fibers are continuous and unidirectional. Parallel to the fibers, the modulus of elasticity may be as high as:

$$
E_{c} \|=f_{m} E_{m}+f_{f} E_{f}
$$

However, when the applied stress is very large, the matrix beings to deform and the stressstrain curve is no longer linear (figure 3). Since the matrix now contributes little to the stiffness of the composite, the modulus can be approximated by:

$$
E_{c} \|=f_{f} E_{f}
$$

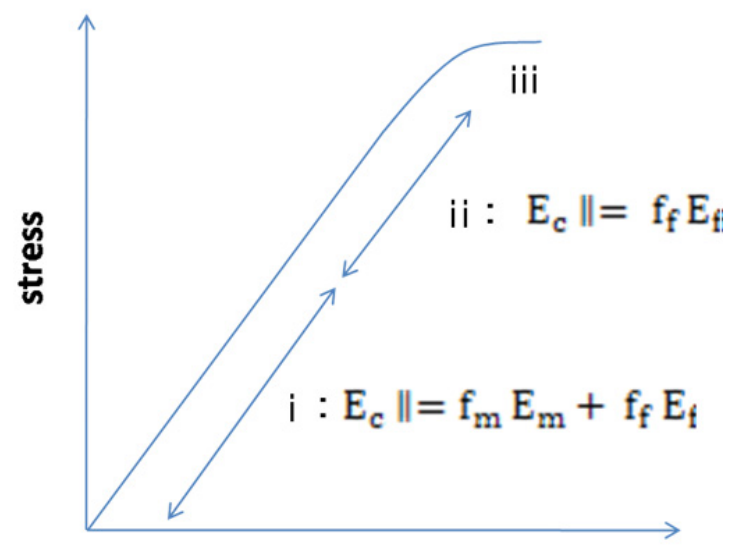

\section{Strain}

Figure 3. The stress strain curve for fiber- Reinforced composite. At low stresses (region i ), the modulus of elasticity is given by the rule of mixtures. At higher stresses (region ii ), the matrix deforms and the rule of mixture no linger obeyed.

When the load is applied perpendicular to the fibers, each component of the composite acts independently of the other. The strain of composite is according to the rule of mixture.

$$
\varepsilon_{\mathrm{c}} \|=\mathrm{f}_{\mathrm{m}} \varepsilon_{\mathrm{m}}+\mathrm{f}_{\mathrm{f}} \varepsilon_{\mathrm{f}}
$$

And it could be change to relation 6 .

$$
\frac{\sigma_{c}}{E_{c}}=f_{m}\left(\frac{\sigma_{m}}{E_{m}}\right)+f_{f}\left(\frac{\sigma_{f}}{E_{f}}\right)
$$


Since $\sigma_{\mathrm{c}}=\sigma_{\mathrm{m}}=\sigma_{\mathrm{f}}$ then the modulus of elasticity for perpendicular load applied condition is according to relation 7 .

$$
\frac{1}{E_{c, 1}}=\frac{f_{m}}{E_{m}}+\frac{f_{f}}{E_{f}}
$$

Tensile strength of FRP composites (TSc) depends on the bonding between the fibers and the matrix. However, the rule of mixtures is sometimes used to approximate the tensile strength of a composite containing continuous parallel fibers:

$$
\mathrm{TS}_{\mathrm{c}}=\mathrm{f}_{\mathrm{m}} \sigma_{\mathrm{m}}+\mathrm{f}_{\mathrm{f}} \mathrm{TS}_{\mathrm{f}}
$$

Where $\mathrm{TS}_{\mathrm{f}}$ is the tensile strength of the fiber and $\sigma_{\mathrm{m}}$ is the stress acting on the matrix when the composite is strained to the point where the fiber fractures. Thus, $\sigma_{\mathrm{m}}$ is not the actual tensile strength of the matrix. Other properties, such as ductility, impact properties, fatigue properties, and creep prosperities, are difficult to predict even for unidirectional aligned fibers.

Many factors must be considered when designing a FRP composite, including the length, diameter, orientation, amount and properties of fibers, matrix and bonding between fibers and matrix.

In the case of fibers length and diameter it should be considered that fibers can be short, long or even continuous. Their dimensions are often characterized by the aspect ratio $l / d$, where $l$ is the fiber length and $d$ is the diameter. Typical fibers have diameter varying from $10 \mu \mathrm{m}$ to $150 \mu \mathrm{m}$.

The strength of composite improves when the aspect ratio is large. Fibers often fracture because of surface imperfections. Making the diameter as small as possible gives the fiber less surface area and, consequently, fewer flaws that might propagate during processing or under a load. The long fiber is more preferable. The ends of a fiber carry less of the load than the remainder of the fiber, consequently, the fewer the ends, the higher the load ability of the fibers (figure 4).

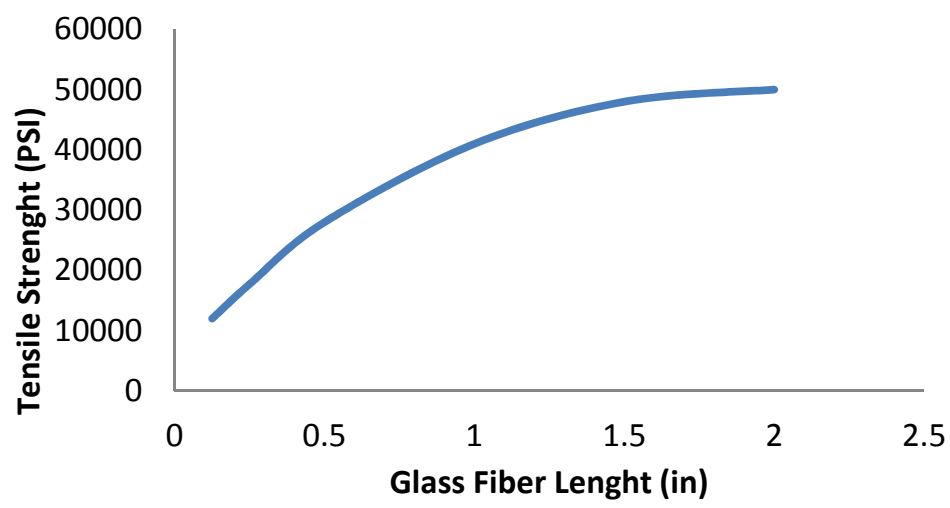

Figure 4. Increasing the length of chopped E-glass fibers in a polyester matrix increases the strength of the composite. 
In many FRP systems, discontinuous fibers with an aspect ratio greater than some critical value are used to provide an acceptable compromise between processing ease and properties. A critical fiber length $l_{c}$ for any given fiber diameter $d$ can be determined by relation 9 .

$$
l_{c}=\frac{T S_{f} d}{2 \tau_{i}}
$$

Where $\mathrm{TS}_{\mathrm{f}}$ is the strength of the fiber and $\tau_{i}$ is related to the strength of the bond between the fiber and the matrix, or the stress at which the matrix begins to deform. If the fiber length $l$ is greater than about $15 l_{c}$, the fiber behaves almost as if it was continuous. The strength of the composite can be estimated from relation 10 .

$$
\sigma_{c}=f_{f} T S_{f}\left(1-\frac{l_{c}}{2 l}\right)+\mathrm{f}_{\mathrm{m}} \sigma_{\mathrm{m}}
$$

Where $\sigma_{\mathrm{m}}$ is the stress on the matrix when the fibers break.

Amount of fibers is another factor which controls the strength and stiffness of composite. As we expect from rule of mixture the greater volume fraction of fibers means the more strength and stiffness of the composite. However, the maximum volume fraction is about $80 \%$, beyond which fibers can no longer be completely surrounded by the matrix [1].

Orientation of fibers also could change the amount of strength and stiffness of the composite. The reinforcing fibers may be introduced into the matrix in a number of orientations. Short, randomly oriented fibers having a small aspect ratio are easily introduced into the matrix and give relatively isotropic behavior in the composite.

Long or even continuous unidirectional arrangements of fibers produce anisotropic properties, with particularly good strength and stiffness parallel to the fibers. These fibers are often designated as $0^{\circ}$ piles, indicating that all of fibers are aligned with the direction of the applied stress. However, unidirectional orientations provide poor properties if the load is perpendicular to the fibers (figure5).

In most FRP composites the fibers are strong, stiff and lightweight. If the composite is to be used at elevated temperatures, the fiber should also have a high melting temperature. Thus the specific strength and modulus of elasticity of the fiber are important characteristic. In specific characteristic, density has an important role. The lighter the material, the more strength and stiffness. Relation 11 and 12 show the specific strength and modulus. Where $\rho$ is density of the composite.

$$
\begin{aligned}
& \text { Specific Sternght }=\frac{T S}{\rho} \\
& \text { Specific Modulus }=\frac{E}{\rho}
\end{aligned}
$$

\subsection{Flexural properties}

Three point flexural tests were conducted to assess the effects of outdoor environments on the flexural strength of FRP composite. The specimens were tested with the exposed surface 
in compression; in general, however, failure occurred in tension at mid span of specimens. Figure 6 shows flexural strength of ASTM standard, original and acid immersed FRP specimens. The matrix of the specimens is polyester and the reinforcement is E-glass. The specimens were kept for 15 years in storage. Hence, the environmental factors such as humidity, weathering and UV light could lead to aging of them and decrease flexibility of specimens. Furthermore, for increasing the effect of aging the specimens were immersed in acid solution $(\mathrm{HCl} 30 \%)$ at $50^{\circ} \mathrm{C}$ for interval of 7,14 and 21 days. The results show that the flexural strength is decreased by aging of composite as well as tensile strength.

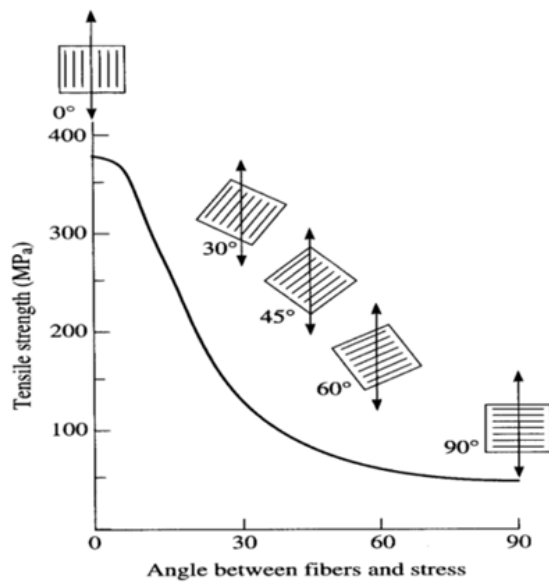

Figure 5. Effect of fiber orientation on the tensile strength of FRP composite. The most strength obtains where the force is applied along the fibers and the least is where the force is applied perpendicular to the fibers.

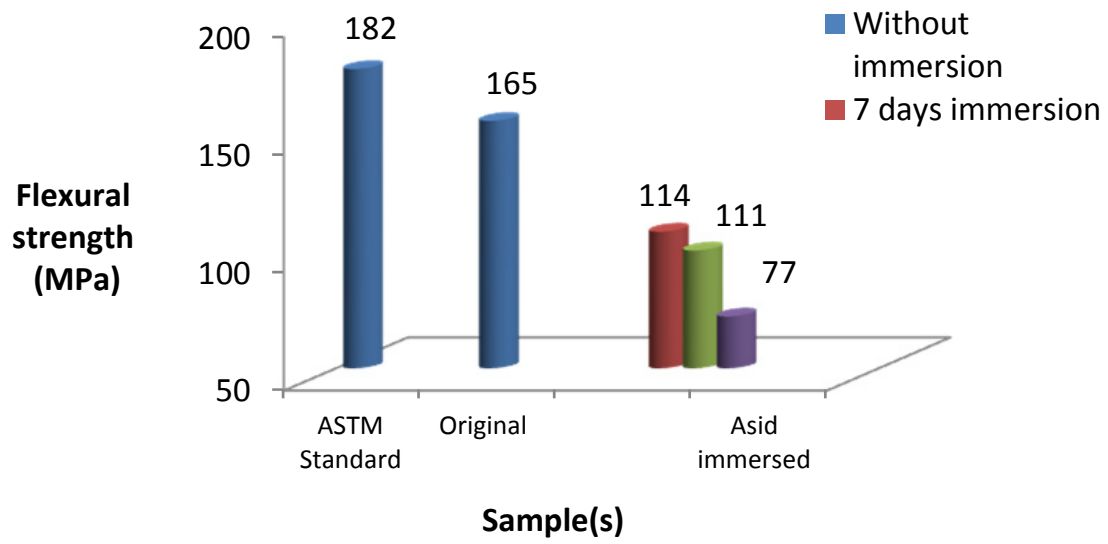

Figure 6. Figure6. Comparison of Flexural strength of FRP specimens (ASTM standard, Original or non immersed and immersed samples). The original samples were stored aged for 15 years. And the immersed samples are the original ones which were immersed at $50^{\circ} \mathrm{C}$ for different intervals. 
By comparison between standard and tested specimens it is revealed that the flexural strength shows $10 \%$ decrease after 15 years storage aging. By immersion at $50^{\circ} \mathrm{C}$ in acid the samples showed gradual deterioration in flexural strength. The results show that storage aging and acid immersion effect on flexural strength is much less than the effect on tensile strength.

The bending displacements corresponding to the flexural strength of the samples (i.e. original, 7,14 , and 21 days immersed samples) at $50^{\circ} \mathrm{C}$ are also shown in figure 7 . Acid immersion caused the gradual decrease of bending displacement similar to the tensile and flexural properties. It seems that penetration of acid made the samples less flexible and more rigid.

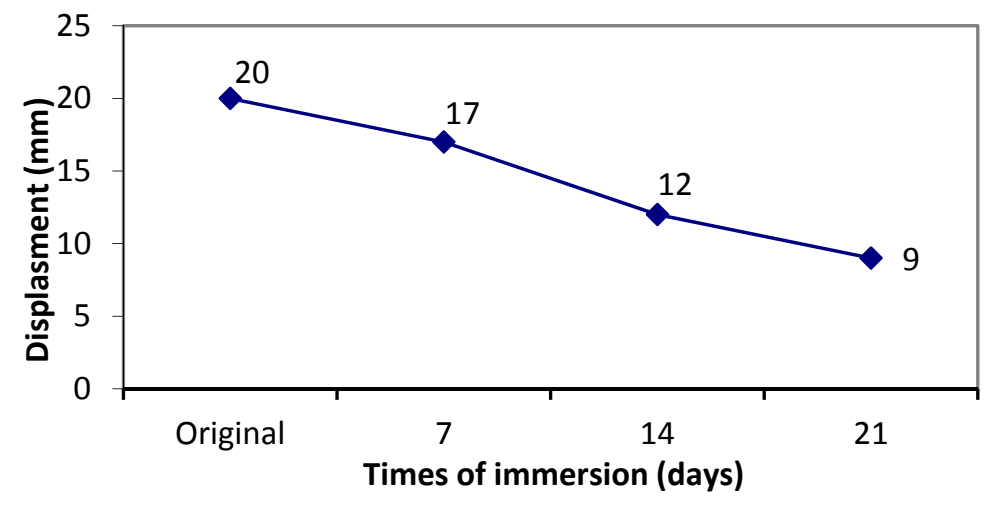

Figure 7. Displacement of original and acid immersed samples due to flexural test. The more immersed samples, the less flexibility and displacement.

When the FRP samples are in contact with the mineral acid solution environment, acid diffuses into the macromolecule of the polymer, degrades the matrix, reinforcements and interfaces. The absorption of acid at different times and temperatures accelerated the rate of aging. Thus reduction of mechanical properties such as tensile strength, flexibility, modulus of elasticity and elongation at break occurred. The effect of this highly destructive process is evidenced by swelling, discoloration and decrease in the mechanical properties of the samples. Chemical attack of polyester matrix by the acid solution environment led to hydrolysis of esters groups of the matrix. Since these groups are located in the chain backbone of the polymer, chain scission occurs. The decrease in molecular weight due to this scission can lead to the reduction in the mechanical properties.

Also the reduction in the flexural strength of the original samples is explained by weathering and thermal degradation. Although the specimens were not suffered by direct exposure of sun light, UV light exists in the environment and could harm the matrix. Weathering is initiated by the absorption of UV radiation by chromophores and in the activation of excited states in the macromolecules. When a polyester composite is exposed to 
a source of energy (solar or thermal) the absorbed energy by the polymer matrix results in the formation of free radicals. Once free radicals have been produced, reaction with oxygen generates hydroperoxides. These hydroperoxides can dissociate further to produce a series of decomposition products including aldehydes and ketones. Decrease of the flexural properties is due to the formation of these products and scissoring of polymer macromolecules. Regarding to the storage period of specimens, heat, moisture and air-born pollution all influence the mechanism of degradation [6].

\subsection{Toughness of FRP}

The toughness $\mathrm{G}_{\mathrm{c}}$ of a composite (like that of any other material) is a measure of the energy absorbed per unit crack area. If the crack simply propagated straight through the matrix (toughness $G_{c}^{m}$ ) and fibres (toughness $G_{c}^{f}$ ), we might expect a simple rule-of-mixtures.

$$
G_{c}=f_{f} G_{c}^{f}+f_{m} G_{c}^{m}
$$

But it does not usually do this. We have already seen that if the length of the fibers is less than $l_{c}$, they will not fracture. And if they do not fracture they must instead pull out as the crack opens (Figure 8). This gives a major new contribution to the toughness. Where the matrix shear strength is $\tau_{i}$, then the work done in pulling a fiber out of the fracture surface is given approximately by relation 14 .

$$
\int_{0}^{l / 2} F d x=\int_{0}^{l / 2} \pi d \tau_{i} x d x=\pi d \tau_{i} \frac{l^{2}}{8}
$$

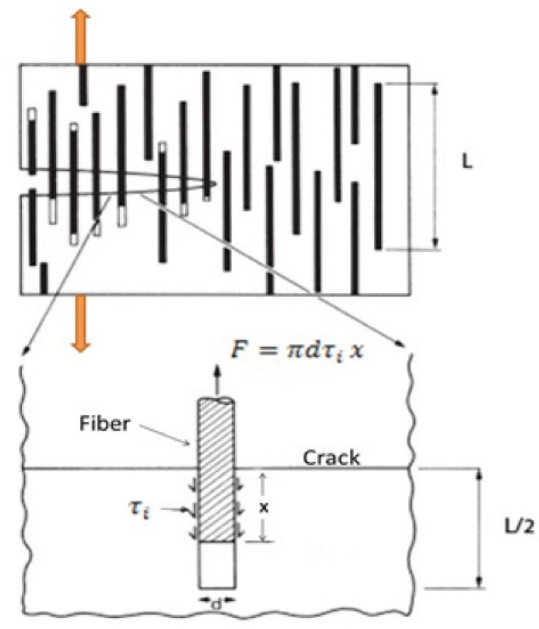

Figure 8. Propagation of crack in a FRP composite.

The number of fibers per unit crack area is $4 V_{f} / \pi d^{2}$ (because the volume fraction is the same as the area fraction on a plane perpendicular to the fibers). So the total work done per unit crack area is: 


$$
G_{c}=\pi d \tau_{i} \frac{l^{2}}{8} \times \frac{4 f_{f}}{\pi d^{2}}=\frac{f_{f}}{2 d} \tau_{i} l^{2}
$$

This assumes that $l$ is less than the critical length $l_{c}$. If $l$ is greater than $l_{c}$ the fibers will not pull out, but will break instead. Thus optimum toughness is given by setting $l=l_{c}$ in equation 15 to give :

$$
G_{c}=\frac{f_{f}}{8} \frac{\left(T S_{f}\right)^{2} d}{\tau_{i}}
$$

The equation says that, to get a high toughness, you should use strong fibers in a weak matrix (though of course a weak matrix gives a low strength). This mechanism gives CFRP and GFRP a toughness $\left(50 \mathrm{~kJ} \mathrm{~m}^{-2}\right)$ far higher than that of either the matrix $\left(5 \mathrm{~kJ} \mathrm{~m}^{-2}\right)$ or the fibers $\left(0.1 \mathrm{~kJ} \mathrm{~m}^{-2}\right)$; without it neither would be useful as an engineering material [7].

\section{Degradation and aging of FRP composites}

The extensive application of composites has seen the emergence of durability problems specific to these materials where durability relates to the long-term performance under adverse conditions, often 20 or even 50 years exposure. These problems are associated with in-service environmental conditions and handling procedures (including maintenance, repair and modifications). Durability is a serious issue from both a health and safety aspect and in terms of economic costs. For large structural applications, such as aircraft, bridge and offshore construction, composite parts are very expensive and due to "parts integration" are often very large. The lack of resistance of composite structures to degradation agents often becomes apparent within a short period. In some circumstances, only a few hours of exposure may lead to catastrophic failure or seriously compromise structural integrity. Irreversible property changes in polyester matrix composites can be induced by any number of degradation agents such as (1) Thermal - static heat ageing, sub-zero exposure or thermal cycling; (2) Humidity (including hot/wet) exposures; (3) Complete immersion in water at ambient and elevated temperatures; (4) Freeze/thaw and dry/wet cyclic conditions; (5) Continuous or intermittent saltwater immersion or spray; (6) Weathering (including rain and sand erosion); (7) Combined load (i.e. stress) and environmental exposures; (8) Chemical (including water, fuel, acids, alkalis, solvents and oxygen); (9) Ultraviolet and high-energy radiation; (10) Electrical stress (e.g. lightning stress and galvanic reactions) and Micro-organisms (e.g. fungi).

In many applications, composite structures will be exposed to a combination of two or more factors, often resulting in complex synergistic degradation of the material. Accelerated degradation may be caused by the combined action of two or more vectors (e.g. temperature and humidity). The relative importance of each agent will depend on the agents present and their levels. Degradation from one agent can also reduce resistance to other agents, similar to biological systems. The two predominant factors in climatic exposure are humidity and temperature. The severity of these two factors will depend on geographical location, and need to be taken into account when designing with these materials. 
Failure of polyester composites may occur because of cumulative damage to the matrix, interfacial separation with the fibers, chemical attack of the fibers or a combination of two or more of these processes. The net effect is loss of stiffness and mechanical integrity. This section examines the degradation of composite materials and constituent components (i.e. fiber, matrix, fiber-matrix interface and interphone) as a result of exposure to aggressive environments.

\subsection{Thermal ageing}

Thermal degradation refers to the chemical and physical processes in polyesters that occur at elevated temperatures. Increased temperature accelerates most of the degradation processes that occur in polyesters such as oxidation, chemical attack and mechanical creep. Oxidation is generally considered to be the most serious problem when using polyesters at elevated temperatures. The influence of temperature on the oxidation processes will depend on the chemical structure of the polyesters. Thermo oxidation is initiated by the reaction of free radicals $\mathrm{P}^{\circ}$ with oxygen to form peroxide radicals:

$$
\mathrm{P}^{\circ}+\mathrm{O} 2 \rightarrow \mathrm{PO}^{\circ}
$$

All polyesters contain these free radicals due to their polymerization and processing history. However, the concentration of free radicals can be significantly increased by interaction with light, ionizing radiation or the presence of transition metals. Once formed the peroxide radicals undergo slower propagation reactions that breakdown the polyester chains. The overall degradation process will normally involve a relatively long induction period during which little degradation is observed. At the end of this period there is a rapid increase in degradation leading to a significant reduction in the mechanical properties of the polyester. This induction period is temperature sensitive and is reduced significantly at elevated temperatures. The induction period of the degradation process can normally be regarded as the serviceable lifetime of the polyester.

Other physical changes can occur in the polyesters at elevated temperatures, one of the most common being thermal expansion. Thermal expansion is reversible and in general does not significant affect the life expectancy of a polymer. However, in polyester composites the mismatch between the thermal expansion of the polyester matrix and the fibers may cause thermo-mechanical degradation during thermal cycling.

\subsection{Weathering}

Weathering or more specifically photo-oxidation of polyesters refers to the chemical and physical changes that occur when radiation is absorbed by a polymer. Photo-degradation is initiated by solar radiation, which results in the absorption of UV radiation by chromophores and in the activation of excited states in macromolecules. However, other climatic quantities such as heat, moisture and air-born pollution all influence the mechanisms of degradation and the subsequent results of ageing. 
When a polymer is exposed to solar radiation the energy absorbed by the polymer results in the formation of free radicals within the polymer by the dissociation of the $\mathrm{C}-\mathrm{H}$ bonds in the polymer chains.

$$
\mathrm{PH} \rightarrow \mathrm{P}^{\circ}+\mathrm{H}^{\circ}
$$

The extent of this chemical reaction depends on the radiation exposure that is the quantity of ultraviolet light $(<350 \mathrm{~nm})$ to which it is exposed. Once free radicals have been produced, reaction with oxygen generates hydro peroxides $(\mathrm{POOH})$.

$$
\begin{gathered}
\mathrm{P}^{\circ}+\mathrm{O} 2 \rightarrow \mathrm{POO}^{\circ} \\
\mathrm{POO}^{\circ}+\mathrm{PH} \rightarrow \mathrm{POOH}+\mathrm{P}^{\circ}
\end{gathered}
$$

These hydro peroxides can dissociate further to produce a series of decomposition products including aldehydes and ketones. The presence of these carbonyl groups in a degraded polyesters can be used as a chemical index for degradation. When these free radicals formed, it can continue to react via propagation reactions long after the initial UV exposure has ended. Termination of these free radical reactions is normally achieved through the reaction of pairs of free radicals.

$$
\mathrm{P}^{\circ}+\mathrm{P}^{\circ} \rightarrow \mathrm{P}-\mathrm{P}
$$

The formation and propagation of free radicals in itself does not serious affect the mechanical properties of the polymer, as they do not significantly alter the long-chain nature of the polymer molecules. Degradation of the mechanical properties occurs because the free radicals produced are highly unstable and readily undergo chain scission reactions. This results in the formation of two smaller polymer chains which each of them is a free radical and they are capable of further reactions. These reactions continuo and go on and on.

Fortunately the intensity of the UV radiation decreases with increasing depth in the material, so that the reaction tends to be a near surface process. Since oxygen is involved in the reaction process, there is an important balance between UV radiation and oxygen diffusion, and of course temperature since that will also determine the kinetics of reaction and the transport of reactive species.

\subsection{Chemical degradation}

Chemical attack of polyesters involves specific chemical reaction of the polymer with the fluid with the most common mode of failure being hydrolysis by water, acids and alkalis. Esters, and carbonate groups are particularly susceptible. Where these groups are located in the backbone chain rather than the side chain, chain scission ensues. A general hydrolysis scheme can be summarized as follows (figure9):

The reduction in molecular weight consequent upon chain scission can lead to a reduction of toughness and fracture strain. Stress is known to accelerate the chain scission process and also to enhance the rate of fluid uptake. 


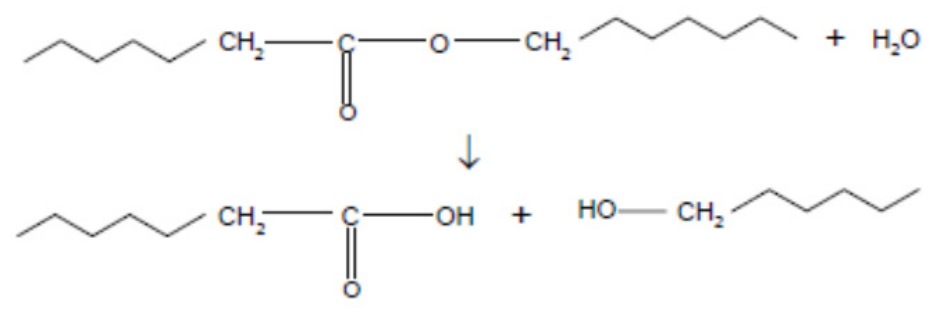

Figure 9. Hydrolysis scheme of polyester due to chemical attack.

\subsection{Environmental stress cracking}

Environmental stress cracking (ESC) remains one of the most common causes of failure in polyester matrix composites. The main reason for this is the complexity of the phenomenon, the agents such as chemical compatibility, liquid diffusion, craze formation and crack development all involve in this phenomenon. While crystalline and amorphous polymers are both susceptible to ESC, amorphous polymers are particularly susceptible due to their relatively open structure that leads to easy fluid penetration. Once the fluid has penetrated to the polymer it becomes locally dissolved and promotes cracking and crazing in the polymer. Cracking is normally preceded by the formation of crazes initiated at sites of stress concentration or at regions of local micro structural inhomogeneity. Crazes are voids that are held together by highly drawn fibrils, which bridge the void allowing the craze to transmit stress and prevent the craze from propagating. The mechanism of crazing in chemical environments is generally considered to be identical to that in air. In general terms craze initiation is considered to evolve from micro deformation processes in localized regions about $30 \mathrm{~nm}$ in diameter.

As the deformation region develops, further localized deformation is induced. The growth and coalescence of such deformed nuclei create a narrow plastic zone. In the presence of dilatational stress, voids develop. This voided structure is considered the precursor of the fibrillated craze structure that ultimately leads to failure. The environment accelerates the craze formation process by local plasticization, for example enhancement of the local relative movement of molecular chains by reduced intermolecular interaction between chains.

\subsection{Ionizing radiation}

Ionizing radiation covers a wide range of different forms of radiation including $\mathrm{x}$-rays, gamma rays, neutrons, alpha particles and beta particles. When a polyester composite is irradiated by the ionizing radiation it will be degraded by the formation of free radicals or ions in the polyester. These reactive intermediates are capable of initiating chemical reactions which occur by free radical or ionic mechanisms and which result in scission as well as in cross-linking reactions. Free radicals with a long lifetime, which are present in the bulk of the material after irradiation, are responsible for changes in properties even a long time after exposure. 
The intensity of ionizing radiation on the earth's surface is not normally high enough to significantly affect most plastics, hence radiation degradation is only occurred in connection with nuclear plants and where radiation is used for applications such as medical x-rays, sterilization or cross-linking.

\subsection{Effect of moisture and water on FRP composite performance}

Most FRPs will absorb small, but potentially Damaging amounts of moisture from the surrounding environments with the degree of degradation linked directly to the amount of moisture absorbed. The absorbed water may adversely affect the material in a number of ways as like as (1) dimensional changes (swelling); (2) reduction in the glass transition temperature $T_{g}$ of the resin and (3) reduction in mechanical and physical properties (i.e. stiffness, strength and hardness). In many instances, water reacts with the matrix and causes irreversible chemical

changes and diminished performance. Capillary action along the fibers can account for a significant proportion of initial moisture uptake, although a chemically resistant matrix may protect the fibers. Shrinkage of the resin away from the fibers during curing is a contributing factor to the capillary effect. The effect of moisture is to cause hydrolytic breakdown of the fiber matrix interface resulting in a loss in the efficiency of load transfer between the matrix and the fiber reinforcement.

The moisture absorption kinetics of polymer systems differs widely between resin systems and also changes with chemical ageing. The glass transition temperature for a typical polyester resin decreases by approximately $15-20^{\circ} \mathrm{C}$ for a $2 \%$ moisture weight gain. This reduction in $\mathrm{T}_{\mathrm{g}}$ is induced by softening or plastization of the polymer matrix and in some cases by loss of organic additives through leaching to the surrounding media. It is advised that when using FRP products be sure that the maximum operating temperature is at least $30-40^{\circ} \mathrm{C}$ below the $\mathrm{T}_{\mathrm{g}}$ of the polyester (taking into account moisture effects). Table 7 shows the variation of $\mathrm{T}_{\mathrm{g}}$ with moisture content for a composite E glass / polyester[8].

\begin{tabular}{|l|c|c|}
\hline $\begin{array}{l}\text { Material } \\
\text { (Exposure Months) }\end{array}$ & $\begin{array}{c}\text { Moisture Content } \\
(\mathrm{wt} \%)\end{array}$ & $\begin{array}{c}\mathrm{T}_{\mathrm{g}} \\
\left({ }^{\circ} \mathrm{C}\right)\end{array}$ \\
\hline As-received & $0.23 \pm 0.01$ & 94.7 \\
\hline Dry & 0 & 97.0 \\
\hline 1 & $0.27 \pm 0.02$ & 92.2 \\
\hline 2 & $0.34 \pm 0.04$ & 95.5 \\
\hline 3 & $0.56 \pm 0.04$ & 92.3 \\
\hline 4 & $0.39 \pm 0.10$ & 95.2 \\
\hline 6 & $0.54 \pm 0.02$ & 96.3 \\
\hline
\end{tabular}

Table 7. Variation of $\mathrm{T}_{\mathrm{g}}$ with moisture content in an accelerated weathering condition for $\mathrm{E}$ glass/polyester specimens. The increase in moisture content is also generally commensurate with a reduction in $\mathrm{T}_{\mathrm{g}}$. The results shown in this table may be indicative of moisture being mainly limited to the outer layers of the composite. 
Although the process of moisture absorption within the surface layers occurs almost immediately on contact with the environment, moisture diffusion into the bulk material is usually a slow process. It may take weeks to months before a substantial amount of moisture has been absorbed by the composite, and considerably longer periods (i.e. 1-2 years) before the material is saturated. The rate of moisture uptake by a FRP composite is dependent on the temperature, relative humidity, exposure time and mechanical load. At elevated temperatures, the rate of moisture uptake and material property degradation is accelerated. Also the presence of tensile loads accelerates moisture uptake by opening existing internal cavities or voids, and by contributing to micro-crack formation. A FRP composite containing micro-cracks will absorb considerably more moisture than an undamaged laminate. Exposing the wet composite to sub-zero temperatures can further exacerbate this process.

\subsection{Glass fiber degradation}

Fibers degradation is primarily a concerning issue for different fibers which are used in FRP composite in various environments. The tensile strength of freshly drawn E-glass fibers is typically 3.5 GPa. This strength can be fully accomplished, provided the fibers are carefully handled during fabrication to avoid surface damage and are stored in a dry environment. Exposure to humid air will decrease the load bearing capacity of the fibers, resulting in a loss of strength. Carbon fibers are relatively insensitive to moisture, and hence the variability in the tensile breaking stress and strain for carbon fiber tows is noticeably less than for E-glass fiber tows. The loss of tensile strength of E-glass fibers is dependent on exposure time, temperature and degree of humidity. On initial exposure to a humid/water environment, the rate of fiber degradation is relatively rapid, even in safe environments, such as air-conditioned laboratories. The tensile strength is reduced to $3.0 \mathrm{GPa}$ after 3 weeks exposure to standard laboratory conditions $\left(23^{\circ} \mathrm{C}\right.$ and $50 \%$ relative humidity $(\mathrm{RH})$ ). Immersion in water at the same temperature for the same period results in a $20 \%$ reduction $(\sim 2.5 \mathrm{GPa})$. Further strength reduction occurs with increasing exposure time. After 100 days, in air and water the strength is $2.6 \mathrm{GPa}$ and $2.1 \mathrm{GPa}$, respectively. Exposure to boiling water for 24 hours results in a $75 \%$ loss of strength. As a consequence of handling and moisture, an intrinsic tensile strength of $2.0 \mathrm{GPa}$ is often assumed for design purposes.

Degradation of E-glass fibers in water can be mainly attributed to leaching of alkali oxides (sodium and potassium oxide) from the fiber surface resulting in the formation of surface micro-cracks, which act as stress concentrators. The loss of strength can be expected to be permanent at all conditioning temperatures and exposure times. The presence of $\mathrm{Na}^{+}$ions in solution slows down the exchange of alkali ions, such as $\mathrm{NaOH}^{-}$, and restricts entry of $\mathrm{Cl}^{-}$ ions into the silic acid network. Chloride ions slow the degradation process, although only slightly. Under the influence of humidity or water the fiber forms a water skin in which the alkali ions (e.g. $\left.\mathrm{NaOH}^{-}\right)$are leached from the fiber surface and replaced by protons $\left(\mathrm{H}^{+}\right)$. The thickness of the silic acid structure or skin increases with exposure time and is dependent on the temperature and humidity of the surrounding environment. The water surrounding the glass fibers evolves into an aggressive alkali solution as the alkali ions dissolve out of the 
glass, slowly decomposing the glass fibers. Increasing the alkali content of the glass tends to reduce environmental attack from water and alkali solutions. Drying of the composite will remove most of the skin of water adjacent to the fiber, but a small permanent layer with retained water will still remain, and the mechanical properties of the fiber will be permanently degraded. Below reaction shows the chemical reaction of water with a fiber glass. Where $\mathrm{R}$ is $\mathrm{Na}, \mathrm{K}, \mathrm{Ca}, \mathrm{Mg}, \mathrm{Al}$. As with moisture effects, acid and alkali degradation processes are accelerated at elevated temperatures.

$$
-\mathrm{Si}-\mathrm{O}-\mathrm{R}+\mathrm{H}_{2} \mathrm{O} \rightarrow-\mathrm{Si}-\mathrm{O}-\mathrm{R}^{+}+\mathrm{OH}^{-}
$$

In the case of acid environment, the acid come into contact with glass fibers, ionic exchange occurs between the metallic cations (e.g. $\mathrm{Na}$ ions) at the glass surface and the hydrogen ions in the acid solution, resulting in leaching of sodium, potassium, calcium, magnesium, boron and aluminum from the outer layer or sheath of the fiber. The dissolution of the supporting network results in a slight enlargement of the fiber diameter and shortening of the fiber length as longitudinal stresses relax, which is resisted by the unaffected core. As the outer layer becomes depleted, tensile stresses imposed by the core of the fiber build up, which significantly decreases the load capability of the fiber and eventually leads to cracks. Below reaction shows the chemical reaction of acid with a fiber glass [9].

$$
-\mathrm{Si}-\mathrm{O}-\mathrm{Na}+\mathrm{H}^{+} \rightarrow-\mathrm{Si}-\mathrm{O}-\mathrm{H}+\mathrm{Na}^{+}
$$

Figure 10(a) shows micrograph of fracture section of the FRP sample before acid immersion at ambient temperature. From this figure one may notice the closely adherence of fibers. A few fibers are pulled out from matrix when tensile stress was applied. Figure 10(b) shows micrograph of fracture section of the FRP sample after 21 days acid immersion at $35^{\circ} \mathrm{C}$ temperature. It is clear that when tension was applied all the fibers were pulled out of matrix because of the loss bond between matrix and fibers. This figure confirms destructive effect of the acid on the FRP composite structure and shows how acid penetration deteriorates fibers/matrix interfacial bond. During the acid absorption of the interphase, acid solution penetrated into the free space of polymer which induced more new cavities and cracks, and washed out the fibers surface. Thus the interphase gradually is damaged and the cohesive bonds between fiber glass surfaces and the matrix has been retarded. In addition to destructive effect of acid, aging of the specimens intensified the amount of damage imposed to the samples [6].

In the case of alkali attack, the chemical reaction involves a breakdown of the silica network by hydroxide $\left(\mathrm{OH}^{-}\right)$ions and eventually dissolution of all the species in the fiber glass. The glass fibers gradually lose weight and strength when they are in contact with strong alkalis. Immersion in weak caustic solutions at room temperature can result in strength reductions of $30 \%$ within 2 weeks. The rate of degradation of glass fibers to alkalis is not determined by the rate of diffusion, but by the active dissolution of the $\mathrm{SiO} 2$ network. The loss of mass is proportional to time. Acid corrosion resistant glass is only slight more resistant to strong alkalis. Below reaction shows the chemical reaction of alkali with a fiber glass. Where $\mathrm{R}$ is $\mathrm{Na}, \mathrm{K}, \mathrm{Ca}, \mathrm{Mg}$ and $\mathrm{Al}$. 

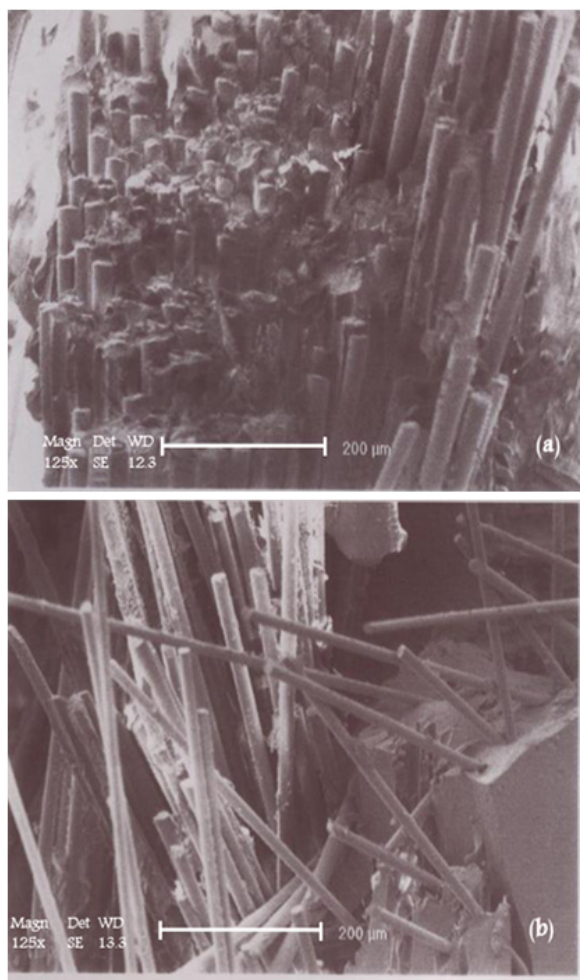

Figure 10. Fracture section of the aged FRP sample before acid immersion (a), after 21 days acid immersion at $35^{\circ} \mathrm{C}$ temperature (b).

$$
\begin{aligned}
& -\mathrm{Si}-\mathrm{O}-\mathrm{R}+\mathrm{H}_{2} \mathrm{O} \rightarrow-\mathrm{Si}-\mathrm{O}-\mathrm{R}^{+}+\mathrm{OH}^{-} \\
& -\mathrm{Si}-\mathrm{O}-\mathrm{Si}+\mathrm{OH}^{-} \rightarrow-\mathrm{Si}-\mathrm{OH}^{+}-\mathrm{Si}+\mathrm{O}^{-}
\end{aligned}
$$

It must be mentioned that the resistance of glass fibers can be improved by modifying the chemical composition. Table 8 shows corrosion resistance comparison between different steels and FRP in hostile environments. It is obvious that FRP materials are resistible in all corrosive environments .However, the amount of resistibility depends on the kind of polyester and fiber, method of production and the grade of hostility.

\begin{tabular}{|l|c|c|c|c|c|c|c|}
\hline \multicolumn{9}{|c|}{$\sqrt{ }=$ unaffected } & $\bullet=$ corroded \\
\hline Material & $\begin{array}{c}\text { Dilute } \\
\mathbf{H}_{2} \mathrm{SO}_{4}\end{array}$ & $\begin{array}{c}\text { Conc. } \\
\mathbf{H}_{2} \mathrm{SO}_{4}\end{array}$ & $\begin{array}{c}\text { Dilute } \\
\mathbf{H C l}\end{array}$ & $\begin{array}{c}\text { Conc. } \\
\mathbf{H C l}\end{array}$ & $\begin{array}{c}\text { Dilute } \\
\mathbf{H N O}_{3}\end{array}$ & $\begin{array}{c}\text { Chloride } \\
\text { Salts }\end{array}$ & $\begin{array}{c}\text { Dilute } \\
\mathbf{N a O H}\end{array}$ \\
\hline FRP (laminate) & $\sqrt{ }$ & $\sqrt{ }$ & $\sqrt{ }$ & $\sqrt{ }$ & $\sqrt{ }$ & $\sqrt{ }$ & $\sqrt{ }$ \\
\hline Carbon steel (1020) & $\sqrt{ }$ & $\sqrt{ }$ & $\bullet$ & $\bullet$ & $\sqrt{ }$ & $\bullet$ & $\sqrt{ }$ \\
\hline Stain less (316) & $\sqrt{ }$ & $\sqrt{ }$ & $\bullet$ & $\bullet$ & $\sqrt{ }$ & $\bullet$ & $\sqrt{ }$ \\
\hline Hastelloy (C) & $\sqrt{ }$ & $\sqrt{ }$ & $\sqrt{ }$ & $\sqrt{ }$ & $\sqrt{ }$ & $\sqrt{ }$ & $\sqrt{ }$ \\
\hline
\end{tabular}

Table 8. Comparison of corrosion resistance of different materials in corroded environments. 


\section{Application of FRP composites}

FRP composites have properties and capabilities that metals lack and they usually cost less than their metals counterparts: austenitic stainless steels, high nickel content alloys, or titanium. FRP is one-fourth the density of steel, which means that in many instances, equipment can be handled manually instead of renting a crane. FRP is easy to repair and does not necessitate arc welding in hazardous areas.

The dielectric properties of FRP means that it can be used safely where electrical conductivity cannot be tolerated. The anisotropic nature of FRP (different physical properties in different directions) enables the engineer to align the fiber reinforcement with the principal strain field, thus making the equipment stronger and lighter than a corresponding steel fabrication.

The applications of composites are not limited to fiber reinforced plastics, either. In another important application, and by no means the only other example, polymer concrete bridge deck overlays provide chloride protection for bridge deck reinforcement steel while restoring roadway profile, durability, and ride quality. The overlays can be placed under a variety of extreme environmental conditions and, as a result, two to four-hour cure times are achievable allowing a rapid return to public traffic.

Whether it is the material itself or its corrosion resistance, all of these advantages translate into better engineered systems that perform better, last longer, and cost less.

Proper applications of FRP often require an understanding or appreciation of the physical and corrosion resistant properties of metals and other common materials of construction. In the case of metals, the table 9 lists some of typical properties in comparison to those of FRP reinforced composites. The properties of FRP can vary with the type of resin and the construction employed for the reinforcement.

Likewise, metal properties may vary considerably depending on the particular alloy or the manner in which the metals have been annealed or pre-processed.

Reinforced composites are not as stiff as most metals, and obviously can be limited in applications requiring high modulus of elasticity. FRP also does not display other favorable properties of metals such as ductility or malleability. On the other hand, FRP features a low density, which can often give a good strength to weight ratio, which is important in transportation and many structural applications. FRP is also a relatively good thermal as well as an electrical insulator. Fabrication or repairs can be made easily, and without the need for arc welding in hazardous areas.

Table 9 compares the principal material properties of FRP to those of various metals. The light weight (density) and the strength to weight ratio of FRP are clear advantages in transportation and in handling. The thermal conductivity is a clear advantage when storing, using, or transporting fluids at elevated temperature. With a thermal conductivity only $1 / 187$ that of carbon steel and 1/900 that of aluminum, heat loss is much less and the hazard that hot equipment poses for workers is reduced. 


\begin{tabular}{|c|c|c|c|c|c|c|c|}
\hline & \multicolumn{2}{|l|}{ FRP } & \multirow{2}{*}{$\begin{array}{c}\text { Carbon } \\
\text { Steel } \\
\text { AISI } \\
1020\end{array}$} & \multirow{2}{*}{$\begin{array}{c}\text { Stainless } \\
\text { Steel } \\
316 \mathrm{~L}\end{array}$} & \multirow{2}{*}{\begin{tabular}{|c|} 
Hastelloy \\
C \\
\end{tabular}} & \multirow{2}{*}{\begin{tabular}{|c|} 
Aluminum \\
$1050-\mathrm{O}$ \\
\end{tabular}} & \multirow{2}{*}{\begin{tabular}{|l|} 
Titanium \\
Grade 12 \\
\end{tabular}} \\
\hline Property & $\begin{array}{l}\text { With Glass } \\
\text { Mat Roving }\end{array}$ & $\begin{array}{c}\text { All } \\
\text { Glass } \\
\text { Mat } \\
\end{array}$ & & & & & \\
\hline Density, lb/in ${ }^{3}$ & 0.065 & 0.050 & 0.284 & 0.286 & 0.324 & 0.098 & 0.163 \\
\hline $\begin{array}{l}\text { Tensile Strength, } \\
\text { psi } \times 10^{3}\end{array}$ & $12-20$ & $10-20$ & 55 & 80 & 80 & 11 & 89 \\
\hline $\begin{array}{l}\text { Yield Strength, psi } \\
\times 10^{3}\end{array}$ & $10-20$ & $9-15$ & 33 & 34 & 51 & 4 & 69 \\
\hline $\begin{array}{l}\text { Modulus of } \\
\text { Elasticity psi x } 10^{6}\end{array}$ & $0.8-1.5$ & $0.7-1.0$ & 30 & 30 & 26 & 10 & 14 \\
\hline $\begin{array}{l}\text { Coefficient } \\
\text { Thermal Expansion } \\
\text { In/in }{ }^{\circ} \mathrm{F} \times 10^{-6}\end{array}$ & 13 & 17 & 7 & 9 & 6 & 13 & 6 \\
\hline $\begin{array}{l}\text { Thermal } \\
\text { conductivity, } \\
\mathrm{Btu} / \mathrm{hr} / \mathrm{ft}^{2} / \mathrm{ft} /{ }^{\circ} \mathrm{F}\end{array}$ & 0.15 & 0.15 & 3 & 9 & 7 & 135 & 11 \\
\hline
\end{tabular}

Table 9. Comparison between mechanical and physical properties of different materials with FRPs.

The reduced tensile strength, coefficient of thermal expansion (at twice that of carbon steel), and modulus of elasticity introduce design considerations that may, at first, appear to be disadvantages to design engineers more familiar with steel, but are, in fact, advantages. The coefficient of thermal expansion (at twice that of carbon steel) may be seen as a disadvantage in the case of applying an FRP liner to a steel substrate, e.g. as in relining a steel tank, but with a modulus 1/30th that of steel, resultant thermal forces in a piping system are only $1 / 15$ th that of carbon steel (because of the lower modulus of elasticity). An actual calculation is necessary to weigh this advantage for thrust blocks in restrained piping systems, since the wall thickness and pipe size also enter into the calculation of the thrust force. Conversely, the lower modulus of elasticity means that pipe guides will be closer together due to the earlier onset of elastic instability [10].

\subsection{Application of FRP composites in aerospace industry}

The composite materials used in aircraft industry are generally reinforced fibers or filaments embedded in a resin matrix. The most common fibers are carbon, aramid, glass and their hybrid. The resin matrix is generally polyester or an epoxy. These systems are requiring curing temperatures between $120^{\circ}$ and $180^{\circ} \mathrm{C}$.

The first structural composite aircraft components, which were introduced during 1950-60, were made from glass fiber reinforced plastics. These components included the fin and the rudder of Grumman E-2A, helicopter canopies, frames, radomes, fairings, rotor blades, etc. Due to high strength and stiffness combined with low density, composites like boron fiber 
reinforced plastics (BFRP) and carbon fiber reinforced plastics (CFRP) were preferred instead of aluminum for high performance aircraft structures. For lightly loaded structures, aramid fiber reinforced plastics (AFRP) which possess low density, have been used. The use of AFRP continues to be restricted to the lightly loaded structures due to the fact that although these fibers possess high tensile strength, they have very low compressive strength. For light aircraft and lightly loaded structural components, glass fiber reinforced plastics (GFRP) has become one of the standard materials. Over the years, use of composite materials has also increased from few small access panels and canopy frames to almost complete airframe surfaces thereby providing weight savings leading to improved performance, reduced drag and also improved durability and corrosion resistance. Consequently, now-a-days, composite materials like GFRP, CFRP and AFRP have become standard materials for flight control surfaces, engine cowlings, fairings, radomes, landing gear doors, floor panels, fan ducts, etc. in aircraft application.

FRP composite materials are being used for different helicopter components as well. Use of advanced FRP composites in helicopter application started way back in 1959 with the development of Optimum Pitch Blade for the XCH-47 twin rotor helicopter of Vertol Aircraft Corporation. There-after, use of composites in helicopter application has been progressively extended to various parts, which include main \& tail rotor blades, stabilizers and fuselage portions. Experience has shown that GFRP main rotor blades have a service life of around 10,000 hours as compared to blades with steel/titanium spars, which have a life of around 1000- 2000 hours.

Flex-beam CFRP rotors are also in use on McDonnell Douglas MD 520N/MD 900 helicopters with NOTAH (No Tail Rotor) system. Composite blades can be designed to be fail-safe and unlike metal blades they do not require frequent inspections for defects. In addition, blade and rotor system efficiencies have been improved due to tailorability of composites. Their longer life and reduced in-service inspection requirements make them very attractive and cost effective.

\subsection{GFRP composites developed for encasing electrical equipment}

Modular enclosures which aid the assembly of electrical switch gear equipment have been introduced into the UK by the Anglo-Douch Holec organization.

By replacing conventional cast iron or sheet steel box with Halyester (a glass fiber-reinforced polyester) containers, the danger of personal contact with electrical voltage has been considerably reduced. As well as its dielectric properties, Halyester is said to be used both indoors and outdoors.

\subsection{Application of FRP composites in off-shore systems}

Today's world FRP is widely used as material of construction for chemical process equipments and storage in chemical off-shore industries. It is considered one of the best materials having high resistance against corrosion and has very high strength and light 
weight and high dielectric properties. It doesn't require any painting and very easy to handle and easily repairable if there is any problem.

In FRP storage tanks generally, the tank shell is filament wounded and top and bottom is hand press molded. Usually tank design is based on international standards like BS-4994, ASTM-D 3299 and ASME section ten.

Although, in FRP storage tanks and vessels selection of materials is depended on parameters like the fluid media and work temperature, generally the reinforcements is EGlass fibers and the matrix material is isopthalic polyester, bisphenole and epoxy based vinylesters. Some off-shore applications are as follows:

- Composite Grids/ Gratings

- Hand rails \& Ladder Components

- Aqueous Piping System

- Water \& fuel storage tanks, Vessels

- Low pressure composite valves

- Spoolable type thermosetting tubes

- Sump Caissons and pull tubes

- Modular paneling for partition walls

- High pressure accumulator bottles

- Flexible \& Floating Risers, Drill pipe

- Sub sea structural components

- Boxes, housings and shelters

- $\quad$ Fire water pump casing \& sea water lift pump casing

- Tendons

- Offshore bride connecting between platforms

- Blast \& Fire protection

\subsection{Application of FRP composites in constructions}

FRP composites have long been used in the construction industry. Applications range from non-structural gratings and claddings to full structural systems for industrial supports, buildings, long span roof structures, tanks, bridge components and complete bridge systems. Their benefits of corrosion resistance and low weight have proven attractive in many low stress applications. An extension to the use of high performance FRP in primary structural applications, however, has been slower to gain acceptance although there is much development activity. Composites present immense opportunities to play increasing role as an alternate material to replace timber, steel, aluminum and concrete in buildings.

Construction holds priority for the adaptation of composites in place of conventional materials being used like doors and windows, paneling, furniture, non-structural gratings, long span roof structures, tanks, bridge components and complete bridge systems and other interiors. Components made of composite materials find extensive applications in shuttering supports, special architectural structures imparting aesthetic appearance, large signages etc. 
with the advantages like corrosion resistance, longer life, low maintenance, ease in workability, fire retardancy etc.

Natural fibers, as a substitute for glass fibers in FRP composite components, have gained interest in the last composite ceiling panel decade, especially in the housing sector. Fibers like flax, hemp or jute are cheap, have better stiffness per unit weight and have a lower impact on the environment. Structural applications are rare since existing production techniques are not applicable and availability of semi-finished materials with constant quality is still a problem.

\subsection{Application of FRP composite in fan impeller}

The axial flow fans are widely used for providing required airflow for heat and mass transfer operations in various industrial equipment and processes. Energy efficient axial flow FRP fans were developed under the advanced FRP composites. The project focused on improving aerodynamic profile of the impellers by selecting appropriate aerofoil and providing composite structural design to suite specific airflow and pressure requirements towards replacing aluminum and mild steel impellers. Hollow FRP blades reduce material and installation costs and possibility of damage to the fan and drive during sudden stops.

Some example of FRP fans are in cooling towers for power plants, mine ventilation for air heat exchanger, diesel locomotive radiator cooling fan and textile mill humidifiers. The performance of all the above fans was tested in actual field conditions with an efficiency differential as high as $25 \%$ over conventional fans with aluminum impellers.

Also application of these impellers in corroded environment such as ventilating the acidic gas and fumes is so desirable. Because if the rate of corrosion and cost of FRP impellers are being considered in comparison with stainless steels and titanium impellers, the FRP impellers will be more beneficial than the latter.

\subsection{Application of FRP composites in automobile/transportation systems}

Despite the potential benefits of lighter weight and durability resulting from corrosion resistance, advanced composites are not recognized as a material of choice in the near term for automotive applications. Significant changes on a broad spectrum would be required to make advanced composites attractive for widespread commercial use in cars and trucks. The principal barrier is the high cost of the raw and fabricated materials when compared to existing options.

However there are opportunities for advanced composites in specific components in the commercial automotive sector. In specialty vehicles of several types, produced in small numbers advanced composite materials have an opportunity to demonstrate their performance benefits, apart from the requirements of the competitive marketplace. 
The composite industry worldwide is investing in process improvements for the molding of polymer composites using forms of conventional E-glass in mid-level performance resins, both thermoplastic and thermoset. Automobiles segment of composites accounts for about $50 \%$ of the thermoplastic and $24 \%$ of the thermoset composite market in the world. Glassreinforced thermoplastic polymer is a promising material for weight reduction because of the relatively low cost of the fiber, its fast cycle time and its ability to facilitate parts integration. Carbon fiber reinforced polymer is another candidate but will require breakthroughs in cost and manufacturing techniques to be cost effective for high volume production.

\subsection{Application of FRP composites in valves and pumps}

Filament-wound FRP valves can be employed in corrosive environments. They have advantages over both PVC and stainless steel. FRP valves are competitively priced with stainless steel and are roughly one-third the weight of steel valves. In addition, they are four times stronger than comparable moulded PVC valves. One manufacturer makes filamentwound, fibreglass, wall-ball valve in sizes ranging from 2-10. It can be employed in both high- and low-pressure applications and has found wide acceptance in the CPI, petrochemical, marine and pulp and paper industries. The valve has a temperature service range from $-40^{\circ} \mathrm{C}$. It is constructed from continuous glass windings impregnated with a thermoset vinyl ester resin. The exterior has a thick resin coating that provides good resistance to chemicals and attack from ultraviolet light. The valve is also available with fireresistant resin coatings. FRP pumps are available that are used in general industrial, chemical and petroleum products applications. Such a pump is fabricated from $30 \%$ fibreglass filled polyester via injection moulding. Pump gaskets are constructed from Viton, capable of withstanding attack from a wide variety of chemicals. Fasteners in the design are stainless steel. Pedestalmounted units and close coupled, electric motor-driven and hydraulicdriven pumps are equipped with- stainless steel shaft sleeves for added shaft protection. These pumps can be used in a wide range of applications including handling water, brine solutions, acids and many organic solvents having a $\mathrm{pH}$ less than 10 . Advantages are good rugged construction, light weight and resistance to a large number of chemicals to an upper operating temperature of $54.4^{\circ} \mathrm{C}$.

\subsection{Application of FRP composites in grating}

FRP structural products are used in a wide range of industrial construction applications. They have the advantages of high strength, light weight, ease of installation, corrosion resistance, are nonconductive, non-sparking, fire retardant, have a long service life, and, in the case of fibreglass-reinforced grating, are slip resistant. Fibreglass-reinforced grating has been widely accepted for use in corrosive environments for such applications as flooring, bridges, trench covers, stairs, tower packing supports, walkways, ramps and grilles. It is employed as a fire-retardant grate on tank car and truck loading catwalks in the oil refinery 
industry and as antiskid trench cover installations in paper mills. In the metal refining industry, it is used for aisles between cells. In food processing operations where acid conditions exist, FRP grating is employed as floor mats. It has also found use in fencing off high-voltage transformers. FRP grating has approximately one-fourth the specific gravity of steel and roughly two-thirds that of aluminium. In general, fibreglass grating has many of the qualities of metal plus several superior advantages. Gratings can be fabricated from a variety of resins on the market. The particular resin used will depend on the specific corrosion environment for which it is intended. Manufacturers will supply samples of grating for immersion tests or test sections can be installed on the site. Fibreglass grating is available in a plain top surface or a surface that has deeply imbedded grit particles. The latter design is employed in applications where maximum non skid features are required. Particles are fabricated into the structure and, as such, are not worn away after constant exposure to corrosive environment and continuous wear. The material is imbedded with angular silica particles during the laying up process. The product is essentially a matrix of polyester resin. Resin wears faster than the silica grit so the grit profile always protrudes above the resin base. This results in very high friction coefficients, even after many years of service.

\subsection{Application of FRP composites in tank constructions}

Filament-Wound laminate construction of standard vertical FRP tanks is done with automated equipment on a rotating mould called a mandrel. A resin-rich layer of chemically resistant polyester or vinylester is applied uniformly to a specified thickness on an inner surface mat. The mat is usually of a chemically resistant fibreglass reinforcement composition or an organic veil. After the initial layer is applied (approximately 20 millimetre thickness), a second layer of resin-rich, chemically resistant polyester or vinylester is applied uniformly, to roughly a four times greater thickness. The reinforcement usually consists of randomly oriented, chopped strand fibreglass. The next step involves the construction of a filament-wound layer impregnated with isophthalic polyester resin or other suitable resin. The layer thickness depends on the size requirements and the specific gravity design criteria. Generally, the layer composition is comprised of filament winding interspersed with chopped strand fibreglass. The purpose of this third layer is to provide the primary strength characteristics of the vessel. This layer serves to minimize the strain placed on the corrosion barrier to avoid cracking of this layer. The corrosion barrier can undergo cracking to loads considerably below the ultimate strength of the corrosive layer material, resulting in tank failure. As a fourth layer, a resin-rich outer surface mat is applied that is usually of the same thickness as the inner layer. This generally consists of a chemically resistant fibreglass reinforcement or an organic veil that is saturated by spraying with isophthalic polyester resin. The responsibility of the first and second layers is to provide the tank with non-corroding and non-contaminating features. A cross-sectional view of the standard vertical tank wall laminate is illustrated in Figure 11[11]. 


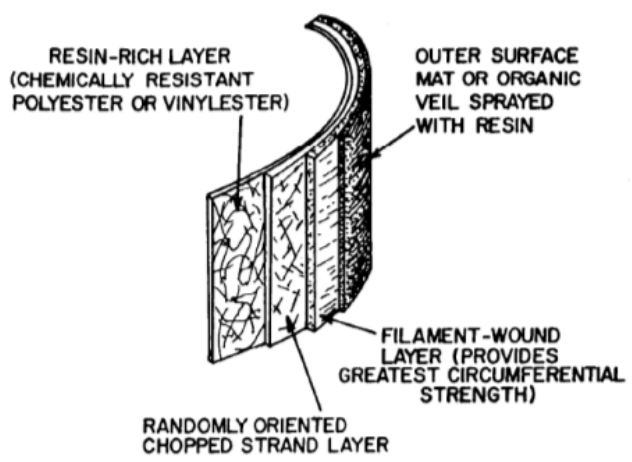

Figure 11. Cross-sectional view of standard vertical tank wall laminate.

\section{Conclusion}

- $\quad$ FRP composites are composed of two materials or phases joined or connected to each other in such a way to give a combination of properties that cannot be attained otherwise. The properties of the individual components, the relative amount of phases, the orientation of various components, the degree of bonding between the phases, the size, shape and distribution of the discontinuous phase are very important in determining the properties of composite.

- $\quad$ Fiber-reinforced polyester composites provide improvements in strength, stiffness and toughness. They also could have corrosion resistance in different hostile environments. By using different glass fibres electrical resistivity is controllable also. Fibres typically have low densities, giving high specific strength and specific modulus, but they often are brittle. Fibres can be continuous or discontinuous. Discontinuous fibres with high aspect ratio $l / d$ produce better reinforcement.

- Fibres are introduced to the matrix in a variety of orientations. Random orientations and isotropic behaviour are obtained using discontinuous fibres; unidirectional fibres produce composites with anisotropic behaviour, with large improvements in strength and stiffness parallel to the fibre direction. Properties can be tailored to meet the imposed loads by orienting the fibres in multiple directions.

- Although the FRP composites are resistant in hostile environments, such environment as well as acidic and alkali ones could deteriorate the interface of fibres and matrix if they contact with the interface directly. So the mechanical properties could decrease if the specimens are in contact with hostile environments intensively.

- FRP composites have different application in construction, aerospace, automotive, sports and other industries.

\section{Author details}

Salar Bagherpour

Islamic Azad University, Department of Materials Science and Engineering, Najafabad-Branch, Iran 


\section{References}

[1] Askland, Donald R. \& P.Phule, Pradeep. (fourth edition). (2003). Composites, In: The Science and Engineering of Materials, (721-765), Thomson Learning, ISBN 0-534-95373-5, USA

[2] Black, T. \& Kosher, R. (tenth edition). (2008). Non Metallic Materials: Plastic, Elastomers, Ceramics and Composites, In : Materials and Processing in Manufacturing, (162-194), John Wiley \& Sons, Inc, ISBN 978-0470-05512-0, USA

[3] Mathews, F. \& Rawlings, R. (1994). Polymer Matrix Composite, In: Composite Materials: Engineering and sciences, (168-200), The Alden Press, Oxford, ISBN 0-412-55960-9, UK

[4] Tuttle, M. (2004), Introduction. In: Structural analysis of Polymeric Composite Materials, (140), University of Washington, ISBN 0-8247-4717-8 USA

[5] Chung, D. (1995). Processing of Carbon Fibres, In: Carbon fibre Composites, (13-49), Butter Worth-Heinemann, ISBN 0-7506-9169-7, USA

[6] Bagherpour, S.; Bagheri, R. \& Saatchi, A. (2009). Effect of Concentrated $\mathrm{HCl}$ on The Mechanical Properties of Storage Aged Fibre Glass Polyester Composite, Vol.30, (271-274), ISSN 0261-3069.

[7] Ashby, M.\& Jones, D. (second edition). (1999). Polymer and Composite, In : Engineering Materials 2, (219-277), Buttere Worth- Heinemann, ISBN 0-7506-4019-7, UK

[8] Broughton, W. (2007). Towards Accelerated Aging Protocols for Service in Hostile Condition. $16^{\text {th }}$ International Conference on Composite Materials. Japan, 16 May 2007

[9] Maxwell, A. \& et al. (2005). Review of Accelerated aging Methods and Life Time Techniques for Polymeric Materials, National Physic Laboratory, ISSN 1744-0270, Scotland

[10] Reich Hold, Inc. (2009). FRP Material Selection Guide, Arailble, From: www.Reichhold.Com/Corrosion

[11] Cheremisionoff, N. \& Cheremisionoff, P.(1995). Fibre Glass Reinforced Plastics, Noyes Publication. ISBN 0-8155-1389-5, USA 